\title{
DOS VISIONES DEL CONFLICTO PETRISTA-TRASTÁMARA: \\ LAS CRÓNICAS DE AYALA Y LAS MEMORIAS DE LEONOR LÓPEZ DE CÓRDOBA
}

\author{
Cecilia Devia ${ }^{1}$ \\ Universidad de Buenos Aires
}

\section{RESUMEN}

Se presentan las diferentes etapas de la confrontación entre los partidarios de Pedro I y Enrique II de Castilla: la formación de ambos bandos durante el reinado de Pedro I, la guerra civil que permitió la superposición de dos reyes durante casi tres años y culminó con la muerte de Pedro en manos de su hermanastro Enrique, y la persistencia de focos petristas durante el reinado de este último. Se emplean específicamente dos fuentes, cada una representativa de uno de los bandos en pugna: las Crónicas de Pero López de Ayala y las Memorias de doña Leonor López de Córdoba, comparando sus diferencias de género, de grados de subjetividad, de objetivos, los posibles públicos a los que estaban dirigidas, la intencionalidad de sus construcciones, etc. La documentación permite ver que la violencia no recae sólo en el individuo implicado en determinado acto, sino que afecta a toda la familia. Se intentará mostrar como, a pesar de que Pedro pasó a la historia como el rey Cruel -en gran parte gracias a las Crónicas de Ayala- desde el bando contrario también hubo formas de violencia que permiten establecer un paralelo.

Palabras clave: Baja Edad Media, Castilla, Violencia, Guerra civil, Crónicas, Memorias.

1 Instituto de Historia Antigua y Medieval "Prof. José Luis Romero", Facultad de Filosofía y Letras, Universidad de Buenos Aires. 25 de Mayo 221 Piso $1^{\circ}$ (1002) Ciudad de Buenos Aires Argentina Correo electrónico: cecidevia@yahoo.com.ar 


\begin{abstract}
We present the various stages of the confrontation between supporters of Pedro I and Enrique II of Castile: the formation of both sides during the reign of Pedro I, the civil war that allowed the superimposition of two kings for nearly three years and culminated in Pedro's murder by his stepbrother Enrique, and the persistence of the petristas foci during the reign of Enrique. Two sources are used specifically, each one representing one of the warring factions: the chronicles of Pero López de Ayala and the Memoirs of doña Leonor López de Córdoba, comparing gender differences in degrees of subjectivity, objectives, potential audiences they were intended, the intention of its_constructions, etc. The sources exhibit that violence does not rest only on the individual subjects involved in any act, but affects the whole family. Although Pedro is known as Pedro el Cruel, in large part due to the Chronicles of Ayala, on the other side there were also forms of violence to establish a parallel.
\end{abstract}

Keywords: Middle Ages, Castile, Violence, Civil War, Chronicles, Memoirs.

\title{
I. INTRODUCCIÓN
}

En este trabajo ${ }^{2}$, centrado en Castilla durante la segunda mitad del siglo XIV, se presentarán las diferentes etapas de la confrontación entre los partidarios de Pedro I y Enrique II: la formación de ambos bandos durante el reinado de Pedro I, la guerra civil que permitió la superposición de dos reyes durante casi tres años y culminó con la muerte de Pedro en manos de su hermanastro Enrique, y la persistencia de focos petristas durante el reinado de este último. Se emplearán específicamente dos fuentes, cada una representativa de uno de los bandos en pugna: las Crónicas de Pero López de Ayala y las Memorias de doña Leonor López de Córdoba.

\section{LAS CRÓNICAS DEL CANCILLER AYALA}

La vida de Pero López de Ayala transcurrió a lo largo de cinco reinados, y él tuvo a su cargo la redacción de las crónicas de cuatro reyes: Pedro I, Enrique

2 Este trabajo forma parte de una tesis de Doctorado en elaboración bajo la dirección del Dr. Carlos Astarita, en el marco del Doctorado en Historia de la Facultad de Filosofía y Letras de la Universidad de Buenos Aires. Asimismo, es una versión ampliada y revisada de una ponencia presentada en las XI Jornadas Internacionales de Estudios Medievales que tuvieron lugar en Buenos Aires del 5 al 7 de septiembre de 2011. 
II, Juan I y Enrique III. Es probable que comenzara a escribir la primera de ellas, la de Pedro el Cruel, después de la batalla de Aljubarrota, por encargo de Juan I.

Respecto a su compromiso personal en este enfrentamiento entre fracciones lideradas por Pedro I y Enrique de Trastámara, Ayala comienza sirviendo al rey legítimo, continuando los servicios a la Corona iniciados durante el reinado del padre de éste, Alfonso XI. En 1354 se adhiere a los nobles sublevados contra el Pedro, que reclaman ante su situación irregular respecto a su esposa, la reina Blanca de Borbón. Ante el fracaso de esta revuelta, participa en la guerra contra Pedro el Ceremonioso de Aragón. Permanece como Alcalde Mayor de Toledo hasta su paso a las fuerzas favorables a los Trastámaras, en 1366. En la batalla de Nájera es tomado prisionero por los ingleses y posteriormente liberado a cambio de un rescate ${ }^{3}$. Esta situación se repetirá, pero de manera más dramática, tras la derrota de Aljubarrota, en $1385^{4}$.

Ayala alterna su vida entre las misiones diplomáticas en el extranjero y los campos de batalla, llegando a recibir en 1398 el título de Canciller de Castilla, que de ahí en más quedará asociado a su nombre. Muere en 1407, tras cuarenta años al servicio de la dinastía Trastámara ${ }^{5}$.

Respecto a las Crónicas de Pedro I y Enrique $\mathrm{II}^{6}$, se acuerda con el criterio de Germán Orduna que las considera como una unidad ${ }^{7}$, recurso que

3 Tovar Júlvez, T. R., "Aspectos caballerescos de las Crónicas de Pero López de Ayala", en Clío, n 32, 2006.

4 Allí, en una situación física deplorable, "cubierto de heridas y quebrados dientes y muelas" -según su propio relato- se despoja de sus insignias de Alférez de la Orden de la Banda y trata de pasar desapercibido entre los numerosos prisioneros. Pero es reconocido y reclamado por el Rey de Portugal, comenzando entonces un regateo sobre la cuantía de su rescate. Ante su persistencia en este forcejeo, termina preso en una jaula de hierro, viéndose forzado a convenir un alto rescate, tal como correspondía a su noble condición. En SÁnCHEz Albornoz, C., "El Canciller Ayala, historiador", en Españoles ante la historia, Losada, Buenos Aires, 1958, pp. 99-136.

5 TOVAR JÚlVEZ, "Aspectos caballerescos...".

6 Rossel, C. (ed.), Crónica del Rey Don Pedro, fijo del Rey Don Alfonso, onceno de este nombre en Castilla. Crónicas de los Reyes de Castilla, 1. Biblioteca de Autores Españoles, LXVI, Madrid, 1953. Rossel, C. (ed.), Crónica del Rey Don Enrique, segundo de Castilla. Crónicas de los Reyes de Castilla, 2, Biblioteca de Autores Españoles, LXVII, Madrid, 1953. Orduna, G. (ed.), Pero López de Ayala. Crónica del rey don Pedro y del rey don Enrique, su hermano, hijos del rey don Alfonso onceno, 2 vol., Buenos Aires, SECRIT, 1994-1997.

7 Orduna, G., "Crónica del rey don Pedro y del rey don Enrique su hermano, hijos del rey don Alfonso Onceno. Unidad de estructura e intencionalidad", en El arte narrativo y poético del Canciller Ayala, CSIC, Madrid, 1998. Para este trabajo se empleará, no obstante, la versión "tradicional" de las dos crónicas en la edición de C. ROSSEL. Tampoco se tratará aquí el tema de las dos versiones, la vulgar y la abreviada, para lo que se remite a GARCIA, M., Obra y personalidad del Canciller Ayala, Madrid, 
habría utilizado Pero López de Ayala para resolver, entre otros, el problema de la superposición de reinados, ya que a raíz de su enfrentamiento ambos hermanastros reinan paralelamente durante más de tres años. Se las consideró como dos crónicas separadas, explica Orduna, siguiendo un criterio externo: “... puesto que desde principios del s. XIV se redactaron crónicas particulares de los reinados de Alfonso $X$ y sus sucesores, $y$ esas crónicas se iniciaban con la proclamación del nuevo rey y terminaban con el relato de su muerte y enterramiento, era lógico pensar que habiendo narrado Ayala los hechos de cuatro reinados, había escrito, por tanto, cuatro crónicas...".

Hasta Ayala, entonces, la "unidad de medida" para las crónicas habría sido el reinado. Habiendo recibido la Crónica de Alfonso Onceno inconclusa, Ayala decidió iniciar su primera Crónica, la de Pedro I, con lo que comúnmente marcaba el final: el entierro del monarca, en este caso el padre de Pedro.

Por otra parte, el “... comienzo de la Crónica de Enrique II -señala Orduna- se da internamente en la Crónica de Pedro I...”. Al producirse la muerte de Pedro, el cronista concluye su relato a la manera tradicional, redactando su semblanza. Ayala debió crear “... una estructura cronística atípica para un caso especial en la historiografía castellana y en la sucesión real del trono de Castilla...". A pesar de que los editores posteriores intentarán con diversos recursos la separación de ambas crónicas, la original unidad interna del conjunto no se pudo borrar completamente, y es la que recupera Orduna en su edición.

\section{LAS MEMORIAS DE DOÑA LEONOR}

Leonor López de Córdoba, nacida a fines de 1362 o comienzos de 1363, relata en sus Memorias, que han llegado inconclusas al presente, las trágicas circunstancias de su vida desde que es puesta en prisión por orden de Enrique II, siendo niña, en las atarazanas de Sevilla, junto a sus familiares y criados, a consecuencia de la profunda lealtad de su padre -Martín López de Córdoba- a la causa petrista. Allí permanecerá por alrededor de nueve años, hasta la muerte el rey, quien deja ordenada en su testamento la liberación de Leonor y de su esposo. Posteriormente Leonor hace referencia a sus esforzados y en gran parte exitosos intentos de recuperar la honra y patrimonio de su linaje, oportunidad en la que llega a ser la principal

\footnotetext{
Alhambra, 1982, y a MARTin, J. L. "Defensa y justificación de la dinastía Trastámara. Las Crónicas de Pedro López de Ayala", en Espacio, Tiempo y Forma, Serie III, Historia Medieval, t. 3, 1990, pp. 157-180.

8

ORDUNA, "Crónica...".
} 
confidente de la reina Catalina de Lancaster, ante la cual finalmente caerá en desgracia.

Las Memorias han sido rescatadas del olvido por la intervención, especialmente, de Alan Deyermond y Reinaldo Ayerbe-Chaux. Este último sostiene que constituyen "... la primera manifestación valiosa del género autobiográfico en España...". La presencia de la forma notarial, agrega, se debe a que fueron dictadas a un escribano, y desde el comienzo expresan "... el propósito ejemplarizante de lo que sigue, muy de acuerdo con la forma de los exempla y de las vidas de santos..."9. Deyermond hace hincapié en lo desconcertante de este olvido por parte de la crítica, teniendo en cuenta que es el "...primer texto atribuido realmente a una escritora mujer en la Península Ibérica..."10.

En su redacción Leonor se ocupa de dejar en claro el esplendor de su origen, tanto materno como paterno, que se ve enriquecido con su unión en matrimonio, a la edad de siete años, con Ruy Gutiérrez de Hinestrosa, aunque el prominente lugar alcanzado en la Corte por ambos linajes se habría conseguido principalmente por los servicios ofrecidos a la Corona ${ }^{11}$. La intensa devoción religiosa de Leonor recorre todo el relato, permanentemente atravesado también por muertes cercanas violentas o especialmente dolorosas, ya sea por efecto de los diferentes avatares políticos, o por la peste ${ }^{12}$.

Como indican González de Fauve y de Forteza, “... La intención manifiesta del relato es reivindicar el honor y prestigio de la familia y rehacer el patrimonio perdido [...] Para ello, en su escrito va a utilizar el linaje y el parentesco como clave de las relaciones de poder..."13.

\section{EL CONFLICTO PETRISTA-TRASTÁMARA}

El inicio de la Crónica de Pedro I de Pero López de Ayala ya parece anunciar los graves conflictos que afectarán su reinado. El cronista describe con su maestría habitual la tensa situación por la que atraviesa el reino ${ }^{14}$, que ya

9 Ayerbe-Chaux, R., "Las Memorias de doña Leonor López de Córdoba", en Journal of Hispanic Philology, Vol. II, nº 1, 1977, pp. 11-33.

10 DeYermond, A., "Spain`s First Women Writers", en Women in Hispanic Literature. Icons and Fallen Idols, Berkeley, 1983, pp.27-52.

11 GonzÁlez de Fauve, M. E. - Forteza, P., "Linaje y poder a través de un escrito femenino: las Memorias de Leonor López de Córdoba (S. XV)", en Meridies: Revista de historia medieval, III, 1996, pp. 17-28.

12 Ayerbe-Chaux, R., "Leonor López de Córdoba y sus ficciones históricas", en Canet Vallés, Beltrán Llavador y Sirera Turo (coord.), Historias y ficciones: coloquio sobre la literatura del siglo XIV: actas del coloquio internacional, 1992, pp. 17-23.

13 GONZÁlez de FAuVE-ForTEZA, "Linaje...".

14 Cr. Pedro I: 1350, III, 405. “... tomaron el cuerpo del Rey, é fueron con él para Sevilla, pasando por Medina Sidonia, que es una villa fuerte, en el camino por dó ellos ivan, 
estaría dividido entre el hijo y la esposa legítimos de Alfonso XI, por un lado, y los hijos bastardos y su concubina, por otro. En esta línea, José Luis Martín indica que en la Crónica de Ayala se empieza a hacer referencia a la tiranía de Pedro I prácticamente desde el comienzo de su reinado, cuando Leonor de Guzmán y sus hijos no se animan a acompañar el cadáver de Alfonso XI a Sevilla por el miedo que tenían al rey ${ }^{15}$. Pero Carlos Estepa Díez distingue entre esta temprana y velada acusación de tirano que haría Ayala a Pedro I desde el comienzo, en 1350, y el surgimiento del proyecto de convertirse en rey que elaboraría posteriormente Enrique de Trastámara, ubicando sus inicios en 1360. La construcción de ese proyecto, que necesariamente debía incluir la propaganda deslegitimadora contra el rey, iría cumpliendo diversas etapas, y uno de sus momentos claves, para Estepa Díez, lo habría desencadenado el

é ladiera el Rey Don Alfonso á Doña Leonor de Guzman, de quien el dicho Rey Don Alfonso oviera fijos al dicho Conde Don Enrique, é á Don Fadrique [...] E Doña Leonor, pasando por la villa de Medina Sidonia, entró en ella: é algunos que con muy grand rescelo é miedo que avia del Rey Don Pedro que nuevamente regnaba, é de la Reyna Doña Maria su madre del dicho Rey, se pusiera en aquella villa de Medina Sidonia, por quanto era suya é era muy fuerte; pero los que sabian la verdad decian que fué por esta manera. Dicen que Don Alfonso Ferrandez Coronel, que era un grand Caballero, é tenia ladicha villa de Medina en vida del Rey Don Alfonso por la dicha Doña Leonor, aquel dia que el cuerpo del Rey pasaban por alli dixo á Doña Leonor: "Señora, ya sabedes como yo tengo de vos por omenaje esta villa de Medina; é pido á vos por merced que la mandedes tomar é entregar á e me quitedes el pleyto é omenage que por ella vos tengo fecho; ca non es mi voluntad de la tener mas de aqui adelante." E dicen que esto facia Don Alfonso Ferrandez porque non queria tener cargo nin vando de la dicha Doña Leonor, nin de sus fijos; ca avia ya tratado sus avenencias con Don Juan Alfonso de Alburquerque [...] E quando Don Alfonso Ferrandez Coronel dixo estas palabras á Doña Leonor de Guzman, ella fué muy turbada, é le pesó mucho dello; ca entendió que los que primero la amaban servir, é en quien tenia esfuerzo, la desamparaban: é respondiole asi: "En verdad, compadre é amigo, en fuerte tiempo me aplazastes la mi villa; ca non sé agora quién por mi la quiera tener." [...] E Doña Leonor estonce entró en la villa, é quitó el pleyto á Don Alfonso Ferrandez; é non falló quien la quisiese tener, nin le facer omenaje por ella. E los que la vieron asi entrar en la villa, coidaron que lo facia por se poner alli con esfuerzo de sus fijos é de sus parientes que venian aquel dia alli, por estar é defenderse, que la villa es muy fuerte. Asi que fué por esta entrada de la dicha Doña Leonor en Medina muy grand movimiento entre los Señores é Caballeros que levaban el cuerpo del Rey, teniendo que la entrada de Doña Leonor en Medina se facia por otra entencion, ca tenia Doña Leonor del Rey Don Alfonso fijos ya grandes é poderosos en el Reyno, é grandes parientes, de los quales estaban aquel dia alli [...] Don Juan Alfonso, Señor de Alburquerque, luego que vida á Doña Leonor entrada en la villa de Medina, trató con algunos de los que ende ivan, que seria bien que estuviesen como presos el Conde Don Enrique, é el Maestre de Santiago Don Fadrique, sus fijos, fasta que viesen lo que facia Doña Leonor. E esto todo súpolo Doña Leonor, é tomó muy mayor miedo por ello; empero luego trataron con ella, é seguraronla, é salió de Medina...".

15 MARTín, "Defensa...". 
propio Pedro I, cuando en marzo de 1366 “... desampara a Burgos”16. Según Estepa Díez, a partir de allí el poder de Enrique crece hasta tal punto en detrimento del de Pedro, que ni siquiera la derrota del conde de Trastámara en Nájera en abril de $1367^{17}$ podrá torcer el destino final de la guerra civil ${ }^{18}$.

Julio Valdeón Baruque indica que "el principal "leit-motiv" de la propaganda trastamarista contra Pedro I era la "tiranía", haciendo referencia con este término "... tanto a la forma de acceso al poder como a su ejercicio". Aunque, según Valdeón, la propaganda trastamarista le hizo a Pedro I esa doble acusación, la versión de que el rey sería hijo del judío Pero Gil, sólo “... debió de circular en ámbitos populares, teniendo poco éxito en la doctrina oficial". Así, a lo que se aludía básicamente con la calificación de "tirano" era "... a la idea de que Pedro I rebasaba los límites impuestos por la ética en el ejercicio del poder". Violentando la doctrina política castellana, Enrique de Trastámara defiende la idea de que el abuso en el ejercicio del poder implicaba la pérdida de la condición regia, siendo "... el más brillante formulador de estas ideas" el cronista Pero López de Ayala. Señala Valdeón: "Un rey tirano, que tenía además la osadía de favorecer a moros y a judíos, se hacía acreedor a la pérdida de su reino [...] No sólo era lícita la separación del trono del rey tirano, sino que su sustituto había actuado como un instrumento de la providencia para poner coto a los desafueros de aquél" 19 .

Para legitimar la usurpación del conde de Trastámara, Ayala emplea con más frecuencia los medios indirectos, tales como cartas de personajes eminentes. Así el propio Enrique, en vísperas de la batalla de Nájera, en su respuesta a una carta que le enviara el príncipe de Gales, aliado de Pedro I, justifica su levantamiento contra el rey legítimo en las acciones monstruosas de su hermano, que le obligaron a asumir una misión avalada por Dios, que le habilita en la práctica para usurpar el reino ${ }^{20}$. Incluso los errores de Enrique

16 Cr. Pedro I: 1366, IV, 539-540.

17 Cr. Pedro I: 1367, XII, 556-558.

18 Estepa DíEz, C., "Rebelión y rey legítimo en las luchas entre Pedro I y Enrique II", en Annexes des CLCHM, Vol. 16, 2004, pp. 43-61.

19 VALDEÓn BARUQue, J., "La propaganda ideológica arma de combate de Enrique de Trastámara (1366-1369)", en Historia. Instituciones. Documentos, 19 (1992) pp. 459467.

20 Cr. Pedro I: 1367, XI, 555-556. "El Rey Don Enrique, desque vió la carta que el Principe le enviaba, rescibió muy bien al su Haraute, é dióle de sus doblas é de sus paños de oro: é ovo su consejo cómo responderia al Principe; porque algunos eran y que decian que porque el Principe non le llamaba Rey en su carta, que él debia escribir cortesmente; ca aun entre los enemigos bien parece ser ome cortés é bien razonado. É mandó luego facer su carta de respuesta para el Principe, la qual decia asi: "[...] é non nos paresce que vos avedes seido bien informado de como ese nuestro adversario, en los tiempos que tovo estos Regnos los rigió en tal manera, que todos los que lo 
son presentados como producto de su respeto al código caballeresco, como el que produjo su derrota en Nájera, al abandonar una posición privilegiada para no tener una ventaja que él consideraba desleal sobre el adversario ${ }^{21}$, en abierta contraposición a las reiteradas actitudes anti-caballerescas de Pedro. En definitiva, en la versión de sus detractores, lo que no se le perdona a Pedro I es la inobservancia del código de honor y el incumplimiento de sus deberes como rey, a los que antepondría sus intereses personales.

José Manuel Nieto Soria sostiene que la guerra civil que enfrentó a Pedro y Enrique supuso “... el momento máximo de confrontación de legitimidades", desarrollando "... un extraordinario despliegue propagandístico" de parte de la facción enriqueña. Pero indica que no constituye un caso excepcional dentro de la Castilla Trastámara, por lo que podría inferirse que sí ha sido fundacional, ya que con el fratricidio de Montiel se instala una nueva dinastía en el reino de Castilla ${ }^{22}$.

saben é oyen se pueden dello maravillar por que tanto él aya seido sofrido en el señorio que tovo. Ca todos los de los Regnos de Castilla é de Leon con muy grandes trabajos é daños é peligros de muertes é de mancillas sostovieron las obras que él fizo fasta aqui, é non las podieron más encobrir nin sofrir: las quales obras serian asaz luengas de contar. É Dios por su merced ovo piedad de todos los de estos Regnos, porque non fiese este mal cada dia mas [...] Dios dió su sentencia contra él que él de su propia voluntad los desamparó é se fué [se refiere a lo que sucedió en Burgos] para los librar de su señorio tan duro é tan peligroso como tenian: é todos los de los dichos Regnos de su voluntad propia vinieron a nos tomar por su Rey é por su señor, asi Perlados, como Caballeros é Fijos-dalgo, é cibdades é villas. Por tanto entendemos por estas sobredichas que esto fué obra de Dios: é por ende, pues por voluntad de Dios é de todos los del Regno nos fué dado, vos non avedes razon alguna porque nos lo destorvar. É si la batalla oviere de ser, sabe Dios que nos desplace dello; empero non nos podemos escusar de poner nuestro cuerpo en defender estos Regnos, á quien tan tenudos somos, contra qualquier que contra ellos quiera ser. Por ende vos rogamos é requerimos con Dios, é con el Apostol Santiago, que vos non querades entrar asi poderosamente en nuestros Regnos faciendo en ellos daño alguno; ca faciendolo, non podemos escusar de los defender. Escrita en nuestro Real cerca de Najara, segundo dia de Abril". É despues que el Principe ovo esta carta, é la mostró al Rey Don Pedro, fué y dicho que estas razones non eran suficientes para su poder escusar la batalla, é que todo esto era en la voluntad de Dios como la su merced fuese de facer, é que non avia otro remedio si non ponerlo á batalla luego.

21 Cr. Pedro I: 1367, XII, 556-558. "El Rey Don Enrique, segund dicho avemos, tenia su Real asentado en guisa que el rio Najarilla estaba entre entre él é el logar por dó avian de venir el Rey Don Pedro é el Principe, é ovo su acuerdo do pasar el rio, é poner la batalla en una grand plaza que es contra Navarrete, por dó los otros venian, é fizolo asi. É desto pesó á muchos de los que con él estaban, ca tenian primero su Real á mayor ventaja que despues le asentaron; pero el Rey Don Enrique era ome de muy grand corazon, é de muy grand esfuerzo, é dixo que en todas guisas queria poner la batalla en plaza llana sin aventaja alguna...".

22 Nieto SoriA, J. M., "Propaganda política y poder real en la Castilla Trastámara: una perspectiva de análisis", en Anuario de Estudios Medievales, n 25, 1995, pp. 488-515. 
En cuanto a la perduración de la campaña antipetrista, si bien Valdeón Baruque sostiene que prácticamente finaliza con el regicidio de Montiel, Covadonga Valdaliso indica:

"El proceso de damnatio memoriae que pone en práctica Enrique II después de Montiel (1369) incluye la revocación de las mercedes otorgadas por Pedro I, la destrucción de gran parte de sus documentos y el reemplazo de su nombre por términos como "hereje" o "tirano". Sólo finalizó, parcialmente, cuando el nieto de Enrique y la nieta de Pedro se casaron en 1388, produciendo un "entronque dinástico" [de las dinastías Borgoña y Trastámara] a partir del cual los monarcas de Castilla descenderían a la vez de los dos reyes. Pero, a pesar de los intentos de Isabel la Católica y de Felipe II de calificarlo como el Justiciero y limpiar su memoria, Pedro es recordado como Pedro el Cruel"23.

La caída en desgracia de los partidarios de Pedro I tiene un testimonio privilegiado en las Memorias de doña Leonor López de Córdoba, hija de Martín López de Córdoba, el que ostentaba entre otros cargos el de Maestre de Calatrava al momento de la muerte de Pedro I. Después de la derrota del rey en Montiel, el Maestre se refugió en Carmona, tras apoderarse de los alcázares, y se encargó de la custodia del tesoro real y de los hijos del rey vencido ${ }^{24}$.

Un episodio clave que desata la furia de Enrique II sucede en el año 1371, durante el prolongado cerco de Carmona, cuando Martín López de Córdoba manda a matar a caballeros partidarios de Enrique II que se habían atrevido a escalar el muro de la ciudad ${ }^{25}$. Cuando pactan entre ambos la rendición de la

23 Valdaliso, C., "Una docta contienda. Correspondencia sobre una crónica perdida del reinado de Pedro i de Castilla (tres cartas inéditas de Jerónimo Zurita, Diego de Castilla y Rodrigo Castro)", en Lemir n 14, 2010, pág. 99-120.

24 Cr. Pedro I: 1369, VII, 590. “... E el Maestre Don Martin Lopez, desque sopo estas nuevas, tornose para Carmona, dó estaban los fijos del Rey Don Pedro, los quales eran estos [...] luego que llegó en Carmona, apoderóse de todo lo que y era, asi del tesoro. como de los alcazares de la villa, que son tres [...] E recogieronse con el dicho Matin Lopez en la villa de Carmona fasta ochocientos de caballo Castellanos y Ginetes, é muchos Ballesteros, é otros muchos que eran alli con él."

25 El número de caballeros implicados varía según las fuentes: son cuarenta para Ayala y doce de acuerdo a las Memorias. Cr. Enrique II: 1371, I, 8. E el Rey Don Enrique ovo su acuerdo de cercar la villa de Carmona do estaba Don Martin López de Cordoba, Maestre que se llamaba de Calatraba, é tenia y los fijos del Rey Don Pedro. E fué el Rey Don Enrique allá, é puso su real sobre la dicha villa, é fizo facer ciertas bastidas enrrededor della, do puso gentes, ca non se podia cercar del todo. E estando sobre Carmona, fizo escalar una torre de la villa de noche, é subieron en ella, quarenta omes de armas muy buenos; é los de la villa, desque lo barruntaron, recudieron alli, é pelearon con ellos, de guisa que, algunos de los que avian subido saltaron contra fuera, é quebrantaron las escalas, é los que avian cobrado la torre non pudieron al facer, é fueron todos tomados. E Don Martin López de Cordoba, Maestre que 
plaza, el rey promete respetarle la vida al Maestre, acuerdo que no cumple, ya que lo manda a ejecutar en Sevilla, junto a otro favorito del rey muerto, Mateo Fernández ${ }^{26}$. Allí se produce también la confiscación de todos sus bienes, a la que se suma la de sus allegados y parientes, a muchos de los cuales se

se decia de Calatraba, desque llegó, fallólos presos á todos los que subieron por el escala, é fizolos todos matar: por lo qual el Rey Don Enrique ovo grand saña é grand sentimiento de Don Martin Lopez, por quanto ficiera matar asi aquellos omes teniendolos en su poder".

Memorias: "... y fué ansi, que quando el Señor Rey Don Pedro quedó cercado en el Castillo de Montiel de su hermano el Señor Rey Don Enrrique, mi Padre bajó el Andaluzia á llevar gente para socorrerlo; y llevandola, halló que era muerto á manos de su hemano; y vista esta desgracia tomó el Camino para Carmona donde estaban las Señoras Ynfantas, fijas del Señor Rey Don Pedro, y Parientas tan cercanas de mi Marido, y mias por mi Madre, y el Señor Rey Don Enrrique viendose Rey de Castilla se vino á Sevilla y puso cerco á Carmona y como es Villa tan fuerte, estubo muchos meses cercada, y acaso haviendo saldio mi Padre fuera de Ella, y sabiendolo los del Real Del Rey [...] ofrezieronse doze Cavalleros á escalar la Villa, y subidos á Ella á la Muralla, fueron presos, y luego fué avisado mi Padre de tal echo, y vino luego, y por el atrevimiento les mandó cortar las Cavezas, y el Señor Rey Don Enrrique visto este fecho, y que no podia por fuerzas de armas entrarle á satisfazerse de este echo, mandó al Condestable de Castilla tratase de medios con mi Padre, y los medios que mi Padre trató fueron dos, el vno que las Señoras Ynfantas las havian de poner libres á Ellas y a sus thesoros en Ynglaterra, antes que El entregase la Villa dicha ál Rey, y asi fué echo...".

26 Cr. Enrique II: 1371, II, 8-9. "Estando el Rey Don Enrique sobre la villa de Carmona, ya las viandas fallescian á los de dentro, é muchos de los que estaban con Don Martin Lopez se partian dende, é se venian para el Rey. E Don Martin Lopez, desque vido que non se podian mas defender, é que non avia acorro ninguno de Inglaterra nin de Granada, traxo su pleytesia con el Rey Don Enrique, que le daria la villa de Carmona é todo lo al que fincaba del tesoro del Rey Don Pedro, ca lo mas avia dado el dicho Don Martin Lopez á los que con él estaban en cuenta de sueldo que les daba. Otrosi que daria preso á Matheo Ferrandez de Cáceres, que fuera Chanciller del sello de la poridad del Rey Don Pedro, que estaba y con él; é que el dicho Don Martin Lopez se fuese en salvo, é el Rey le mandase poner en otro regno do él quisiese, o le ficiese merced si con él quisiese fincar. E al Rey Don Enrique plogo desta pleytesia, é otorgoselo asi: é fué fecha jura al dicho Don Martin Lopez por el Maestre de Santiago Don Ferrand Osores, que el Rey Don Enrique le guardaria el seguro que le avia fecho. E desque todo esto fué asi ordenado, é ovo entregado é complido el dicho Don Martin Lopez todo lo que prometió al Rey, el Rey mandóle prender; é desque fué preso levaronle á Sevilla. E por quanto el Rey le avia sentenciado, é otrosi por la saña que avia dél especialmente por la muerte que ficiera de aquellos omes de armas sus criados del Rey que avian subido por el escala en Carmona, fizolos matar en Sevilla á él é á Matheos Ferrandez. Empero algunos que amaban servicio del Rey, especialmente Don Ferrand Osores, Maestre de Santiago, fué muy quejado, é non le plogo, por quanto el Rey le mandára que asegurase de muerte al dicho Don Martin Lopez, é quejóse mucho dello al Rey; pero non le pudo aprovechar al dicho Don Martin Lopez que non moriese (2). Otrosi el Rey Don Enrique cobró en Carmona muchas joyas de las que fueron del Rey Don Pedro, é le entregaron sus fijos que alli estaban; é el Rey enviolos presos á Toledo, é tornóse el Rey á Sevilla." 
encarcela. Y aquí comienza el trágico relato de Leonor, presa en las atarazanas de Sevilla cuando era una niña, cautiverio que se prolongará por nueve años.

\section{CONCLUSIONES}

Una breve mirada hacia las fuentes empleadas permite hacer algunas primeras comparaciones, las cuales están interrelacionadas. En principio, representan dos géneros diferentes, con todo lo que ello puede implicar. El género cronístico ya tenía una tradición importante al momento en que son escritas las Crónicas de Pedro I y Enrique $\mathrm{II}^{27}$, mientras que, como se manifestó anteriormente, las Memorias de doña Leonor constituirían la primera manifestación autobiográfica de la Península Ibérica ${ }^{28}$. Si bien la lectura de los hechos que hace Ayala dista mucho de ser "objetiva", no hay dudas de que las Memorias expresan una abierta subjetividad, lo que permite un tono de alguna manera intimista.

Las Crónicas constituyen documentos que se podrían denominar oficiales, y fueron hechas por encargo de un rey, mientras que las Memorias surgen sólo ante el deseo de doña Leonor de relatar su historia y la de su linaje. De lo anterior se puede inferir que estaban dirigidas a distintos públicos, aunque en ambos casos se presupone que serían leídas por miembros del estamento noble, si bien es esperable que el público -en especial el contemporáneo a los hechos- al que llegue una crónica regia sea más vasto, entre otras cosas porque la Corona dispone de medios mucho más amplios de difusión que los que dispondría una mujer del estamento medio de la nobleza.

En cuanto a la extensión de los documentos, queda claro que, aunque la versión de las Memorias que ha llegado hasta el presente está inconclusa, nunca alcanzarían las dimensiones de las Crónicas de Ayala.

En ambas fuentes aparece claramente la estrecha relación existente entre violencia y parentesco. En las Crónicas se relatan algunas de sus expresiones más notorias, entre las que se destaca el fratricidio de Montiel $^{29}$, por varias razones: es un acto fundacional, ya que instaura una nueva dinastía; los que se enfrentan son hijos del mismo padre; ambos de hecho son reyes, aunque se discutan diferentes criterios de legitimación ${ }^{30}$. Pero hay otras muertes, que

27 Sobre el género cronístico, ver FUNES, L., "Las crónicas como objeto de estudio", en Revista de Poética Medieval, 1, 1997, pp. 123-144.

28 Ayerbe-Chaux, "Las Memorias...".

29 Cr. Pedro I: 1369, VIII, 590-593.

30 Devia, C., "La lucha fratricida en el "Cuento de los Reyes" (El Victorial) y en las Crónicas del Canciller Ayala", en Anuario de Estudios Medievales, CSIC, n 40/1, enerojunio de 2010, pp. 387-413. 
Ayala describe como violentas, de gran peso desde el punto de vista de la relación anteriormente expuesta: la de la joven reina Blanca de Borbón ${ }^{31}$, la de diferentes hermanastros de Pedro $\mathrm{I}^{32}$, la de la reina madre ${ }^{33}$, etc.

En cuanto a las Memorias, esta relación entre violencia y parentesco queda también trágicamente plasmada en la muerte en manos de la peste sufrida por el hijo de sólo doce años de Leonor, episodio que, si bien no tiene relación con el conflicto analizado en este trabajo, merece destacarse por la extraña actitud de Leonor de no reparar en riesgos para atender al joven judío criado por ella desde que era niño, hasta el punto de exponer a un contagio seguro a su hijo de sangre ${ }^{34}$.

Por otra parte, es evidente que la familia entera se veía afectada por las acciones de sus miembros, y el caso paradigmático podría ser aquí el de la familia de don Martín López de Córdoba. Cuando se habla de familia en este período histórico hay que incluir también a los criados o allegados, quienes en este episodio puntual también son puestos presos en las atarazanas. Un dato que puede llamar la atención actualmente es el hecho de que, en líneas generales, no se hace mención especial a la corta edad de algunos afectados, como es el caso de la propia Leonor, sus hermanos, esposo, cuñados y cuñadas. Si bien Leonor hace mención de ello, especialmente en el crudo relato de la muerte de uno de sus hermanos en prisión, no se muestra un tratamiento diferencial en que la edad aparezca como atenuante o agravante $e^{35}$.

31 Cr. Pedro I, 1361, III: 512-513.

32 Cr. Pedro I, 1358, III: 481-483, Cr. Pedro I, 1359, XXIII: 500.

33 Cr. Pedro I, 1357, II: 476-477.

34 Memorias: “... é yo havia enbiado aquel Huerfano, que crie á Ezija [...] dixeronme: Vuestro Criado Alonso viene con pestilencia [...] y en pensar que por mi havia entrado tan gran dolencia en aquella Casa [...] é por mis Pecados treze Personas, que de noche lo velaban, todos murieron y yo facia una Oracion [...] rogando A Dios que me quisiese librar ámi, y á mis fijos; é si alguno obiese de llevar, llebase, el mayor por que era mui doliente; é plugó á Dios que una noche no fallaba quien velase aquel Mozo Doliente, por que havian muertos todos los que hasta entozes lo havian velado, é vinoá mi aquel mi hijo, que le decian Juan Fernadez de Henestrosa, como su Abuelo, que era de hedad de doze años, y quatro meses é dixome: Señora no hay quien vele á Alonso estanoche? É dijele: Velarlo vos por Amor de Dios; y respondiome: Señora agora que hán muerto Otros quereis que me mate? [...] é mi hijo por no salir de mi mandamiento lo fué á velar, é por mis pecados aquella noche le dió la pestilencia e otro dia le enterré, y el emfermo vivió despues haviendo muerto todos los dichos; é Doña Theresa, muger de Don Alfonso Fernandez mi Primo hubo mui gran enojo, por que moria mi fijo por tal Ocacion en su Casa...".

35 Memorias: “... Y estubimos los demas que quedamos presos nueve años hasta que el Señor Rey Don Henrrique falleció; y nuestros Maridos tenian sesenta libras de hierro cada vno en los pies, y mi hermano Don Lope Lopez tenia una Cadena encima delos hierros en que havia setenta eslabones; El era Niño de treze años, la mas hermosa Criatura que avia en enel mundo, é á mi Marido en especial ponianlo en el Algive 
Así también, al leer sobre todo las Memorias de doña Leonor, queda claro que desde el bando trastamarista hubo formas de violencia con las que puede hacerse un paralelo con las ejercidas por mandato de Pedro I. Incluso el tema del respeto de los valores caballerescos -fundamental en un monarca- de parte de Enrique II, también es puesto en duda en varias ocasiones, aun en las mismas Crónicas.

La visión de este momento histórico puede ser más completa si se tiene en cuenta que, en un contexto de guerra civil, el enemigo no es el Otro, sino un Igual, produciéndose de forma extraordinariamente ampliada fratricidios, parricidios y filicidios, tanto si estos crímenes son vistos desde un punto de vista simbólico -todos los hombres de una ciudad o estado serían hermanos, los mayores ejercen la tutela de los menores- o desde un punto de vista que se podría llamar "textual" o "literal" - en todas las guerras civiles se producen divisiones en el seno de las familias-. Llega un momento en que no parece posible permanecer al margen, haciéndose imperativo tomar partido por uno de los bandos, con todos los problemas que esto implica, más aún teniendo en cuenta el complejo sistema de lealtades que rige en una sociedad de carácter feudal. Durante el transcurso del conflicto se ven afectados todos los grupos sociales, y sus consecuencias perduran hasta mucho después de haber concluido. En un período en que cada hombre vive profundamente inmerso dentro de una amplia red de relaciones, las decisiones tomadas por un individuo afectan además a toda su familia, considerada esta desde el punto de vista de relaciones tanto de sangre como de parentesco espiritual o político.

dela hambre, é tenianlo seis, ó siete dias que nunca comia, ni vebia por que era Primo delas Señoras Ynfantas, hijas del Señor Rey Don Pedro: En esto vino una Pestilencia, é murieron todos mis dos Hermanos é mis Cuñados, é treze Cavalleros dela Casa de mi Padre [...] é á todos los sacaban á desherrar al Desherradero como Moros, despues de muertos á el triste de mi hermano Don Lope Lopez pidió al Alcayde que nos tenian, que dixesen á Gonzalo Ruiz Bolante que nos hacia mucha Charidad, é mucha honrra por amor de Dios: Señor Alcayde sea agora vuestra merced que me tirase estos hierros en antes que salga mi anima, é que no me sacasen al desherradero; á él (dijole) como á moro, si en mi fuese yo lo faria; y en esto salió su anima en mis manos; que havia El un año mas que Yo, é sacaronlo en una tabla ál Desherradero como á Moro, é enterraronlo con mis hermanos, é con mis hermanas, é con mis Cuñados en San Francisco de Sevilla, e mis Cuñados trayan sendos Collares de Oro á la Garganta, que eran cinco hermanos [...] que por sus pecados el Vno murió en Sevilla, y el Otro en Lisbona, y el Otro en Ynglaterra, é asi murieron derramados, é se mandaron á enterrar con sus Collares de Oro, é los frayles con la codicia despues de enterrado le quitaron el Collar. Y no quedearon enla Atarazana dela Casa de mi Señor el Maestre, sino mi Marido y Yo: y en esto murió el mui alto, y mui Esclarecido Señor Rey Don Enrrique de mui Santa y Esclarecida memoria, y mandó en su testamento que nos sacasen dela prision, é nos tornasen todo lo nuestro...". 
En otro orden de cosas, se puede marcar una contradicción, o más bien una paradoja, en el hecho de que Leonor reivindica honor y linaje, valores que, según Ayala, no serían especialmente respetados, sino avasallados en repetidas ocasiones, por Pedro I, monarca a cuyo servicio fue fiel el padre de Leonor incluso hasta después de la muerte del rey.

Para finalizar, un comentario sobre las diferentes racionalidades de la violencia que se pueden encontrar en las fuentes que son objeto de esta investigación. En el caso de las Crónicas, por ejemplo, si bien Ayala parece querer mostrar un uso descontrolado de la violencia regia por parte de Pedro I, su propio relato ofrece indicios que permiten inferir que las acciones del rey estuvieron en gran parte teñidas de racionalidad, siendo llevadas a cabo las más de las veces siguiendo planes minuciosamente calculados, que perseguían determinados objetivos de orden político, social, económico, etc. Comparando diversos pasajes de la Crónica de Pedro I es posible analizar esta dicotomía entre el retrato negativo e irracional que el canciller Ayala -uno de los mayores responsables de que Pedro sea recordado como el Rey Cruel- construye con maestría, y lo que dejan entrever prácticas que él mismo relata. La violencia ejercida por Pedro I es mostrada en general por Ayala como una escalada carente de todo sentido y surgida de su carácter cruel, lujurioso y sanguinario ${ }^{36}$. Pero el estudio detenido de la misma documentación revelaría una política de construcción de poder regio por medio de prácticas en las que intervendrían diferentes funciones de la violencia: económica, socializadora, de intercambio, simbólica, de justicia, fundacional, cultural, etc., cuyo examen y desarrollo no es posible encarar en las breves dimensiones de este trabajo.

36 Devia, C., "La construcción de un rey monstruoso y la legitimación de un usurpador en la Crónica de Pedro I del Canciller Ayala", en AA.VV, Criaturas y saberes de lo monstruoso, volumen 2, Instituto Interdisciplinario de Estudios de Género, Facultad de Filosofía y Letras, Universidad de Buenos Aires (en prensa). 